\title{
Moral Disengagement, Attitudes Towards Violence and Irrational Beliefs as Predictors of Bullying Cognition in Adolescence
}

\author{
Metin Kocatürk ${ }^{1} \&$ Tuğba Türk-Kurtça ${ }^{2}$ \\ ${ }^{1}$ Hasan Âli Yücel Faculty of Education, Istanbul University-Cerrahpaşa, Istanbul, Turkey \\ ${ }^{2}$ Faculty of Education, Trakya University, Edirne, Turkey \\ Correspondence: Metin Kocatürk, Hasan Âli Yücel Faculty of Education, Istanbul University-Cerrahpaşa, \\ Istanbul, Turkey.
}

Received: April 29, 2020

doi:10.5539/ies.v13n10p47

\author{
Accepted: July 1, 2020 \\ Online Published: September 21, 2020
}

URL: https://doi.org/10.5539/ies.v13n10p47

\begin{abstract}
Considering the causes of bullying behavior, the situations caused by it and its impact area, the formation of bullying in the cognitive dimension draws attention. In this context, examination of thoughts or cognition about bullying becomes an important element in explaining bullying. In this study, it is aimed to examine moral disengagement tendencies, attitudes towards violence and irrational beliefs as predictors of bullying cognition of adolescents between the ages of 15-18. Study group consisted of 369 individuals, 197 females and 172 males. Bullying Cognition Scale, Moral Disengagement Scale, Attitude Towards Violence Scale and Irrational Beliefs Scale for adolescents were applied to participants. The data obtained were tested by hierarchical regression analysis. Moral disengagement tendency, attitudes towards violence and irrational beliefs (demands for success and for comfort sub-dimensions) predicted cognition about bullying significantly. It was determined as a result of hierarchical regression analysis that these variables predicted bullying cognition both separately and together. At the end of the study, suggestions for the studies to be carried out for bullying, which would be handled within the scope of cognitive structure, were presented.
\end{abstract}

Keywords: bullying, irrational beliefs, moral disengagement, violence

\section{Introduction}

Bullying is a form of deliberate harm that is constantly inflicted by a stronger person or group (Olweus, 1993, $\mathrm{p}$. 43; Rigby, 2007, p. 15). The difference in power in bullying can be either physical, social, linguistic, or authority (Rigby, 2003, p. 8). In addition to the power abuse mentioned, the victim's not being able to protect himself, bully's getting the benefit of those actions, the bully's delight in what he did, etc. also come into question (Preventing Violence Against Children Project, 2015). Rigby (2003, p. 10; 2007, p. 20) classified bullying as physical bullying, verbal bullying, relational bullying and nonverbal bullying. Physical bullying includes kicking, spitting, throwing things, hiding things, gathering people to attack and similar behaviors. In relational bullying, certain behaviors such as driving a wedge with friends, making friends against someone, forming a coalition could be observed. Nicknaming, making jokes on individuals' image, insult, unfair criticism, ironizing, spreading malicious rumors about it etc. are examples of verbal bullying. Shaking fingers or heads to threaten, intentionally ignoring behaviors imply non-verbal bullying. Generally speaking, although bullying seems to be anger of a strong person towards a weak person, it is a very complicated phenomenon that includes bullies, victims and bystanders (Perdew, 2015). According to Rigby (2002, pp. 65-66; 2003, p. 12), bullying is a dynamic process. Potential victims are selected as a bias object, who exhibits certain characteristics such as worthlessness, weakness, frailness, introversion, anxiousness, etc. The process, which started with mocking and light mocking at the beginning, progresses more with the participation of other children and may even turn into physical bullying. The victim looks sad and weak in this situation, while the bully feels stronger and dominant. Especially others' approval of these actions prevents the bully from empathizing, leading to bullying to continue and increase its severity.

Although it cannot be identified with a single profile, people who exhibit bullying behavior have some common features. The most dominant feature of those who tend to bully is using brute force. In addition, those who exhibit bullying behavior can be defined as those who are aggressive, impulsive, have difficulty in obeying rules, violate the rules consciously, have positive attitudes towards violence and less empathy, and enjoy applying power 
(Olweus, 1993, pp. 56-57). Even, they have such an image that they are popular at school, or have close friends (Perdew, 2015) or try to be popular (Aluede, Adeleke, Omoike, \& Afen-Akpaida, 2008), do not care about the feelings of others and enjoy establishing authority (Smith, Twemlow, \& Hoover, 1999). In addition, males are more involved in bullying events (Erdur-Baker, 2010; Feigenberg, King, Barr, \& Selman, 2008; Perren \& Gutzwiller-Helfenfinger, 2012; Robson \& Witenberg 2013; Turner, 2008). When bullying is taken into consideration in terms of using force, it is thought that bullying behaviors make such a difference in terms of gender.

Although bullying is considered as a sub-category of aggression in the literature (Houndoumadi \& Pateraki, 2001; Pişkin, 2002), it can be excused in real life. In this respect, cognitive assessment of bullying is a prominent issue. When the opinions on bullying are examined, it is seen that bullying is a part of growing (Padgett \& Notar, 2013); mocking can be seen as friendly and fun in daily life (Olweus, 1997). There may be cognitive dynamics such as classifying behaviors such as mocking and naming as low-bullying (Rigby, 2002, p. 42); underestimating other types of bullying according to physical bullying (Forsberg, Thornberg, \& Samuelsson, 2014), seeing aggression as humor (Führ, 2002). However, bullying differs from play and joke due to lack of mutual pleasure or interest (Frey, Hirschstein, Edstrom, \& Snell, 2009). There are also beliefs that everybody is exposed to bullying (Padgett \& Notar, 2013). The perception that the victim himself is strange and perverted (Aluede et al., 2008; Thornberg, 2015) and bullies' being angry and self-confident (Sokol, Bussey, \& Rapee, 2015) may cause the situation to be taken less seriously. It is seen that the perception of bully focuses on their power and status demands and problems (Thornberg, 2015). If the bully is seen more powerful, brave and talented in situations that bullies are favored, the victim is considered to be weaker, fearful and helpless (Baldry, 2004). In fact, people witnessing bullying can enter into a form of misleading burden, with logical justifications that the victim deserves it with the assumption of a fair world (Budak, 2009). Therefore, it is stated that violence has a cultural aspect that is accepted to be applied to some people and some situations (Polat, 2001). Understanding individual-level factors is as extremely important as understanding the social context. More detailed studies are required to understand the mechanisms that ensure the development and continuity of bullying (Bombay, 2002). In this respect, bullying should be handled in the cognitive context. It may also be necessary to address thoughts that may lead to bullying in terms of moral evaluations.

Moral disengagement has been evaluated as cognitive mechanisms that enable people to avoid evaluating themselves negatively when people do not comply with moral standards to get rid of guilt, responsibility, empathy and shame (Bandura, 1999). Thanks to cognitive restructuring, a situation that is not considered morally becomes morally acceptable (Bandura, Barbaranelli, Caprara, \& Pastorelli, 1996). Thornberg (2010) mentions that bullying is seen by students as a deviation, revenge, an entertaining game and that moral departure can be observed in this case. Hymel, Rocke-Henderson, and Bonanno (2005) found that bullying is predicted by moral disengagement and there is especially a trend that legitimizes bullying and blames the victim. They also found that a self-centered perspective dominates and focuses on earnings. Thus, moral disengagement is seen as a dynamic that can explain bullying (Gökkaya \& Sütcü, 2015). In this respect, as a result of moral disengagement, bullying can be considered as a moral distortion in which moral regulation is disabled (Kuasandra, Sunawan, \& Japar, 2020). When it comes to moral disengagement, people can exclude themselves from their immoral behavior (Bandura, 2002). However, when evaluated by gender; moral disengagement of males has been observed to be higher (Caravita, Sijtsema, Rambaran, \& Gini, 2014; Turner, 2008). Males are more likely to use moral disengagement mechanisms to justify their actions (De Caroli \& Sagone, 2014). In addition to using legitimization more, males report lower levels of moral and conscience (Perren \& Gutzwiller-Helfenfinger, 2012).

Another concept that can be related to bullying along with moral considerations is irrational beliefs. Cognitive evaluations are considered as an important factor in understanding thoughts, behaviors and emotions related to bullying. Spirito, Stark, and Williams (1988) stated that in cases where people believe that they cannot cope with the problems, they can blame themselves and the environment and harm their environment as a coping strategy. Irrational beliefs that are composed of strict, dogmatic, unhealthy, compelling content are also called demanding beliefs (Ellis, 2000). Irrational beliefs are examined as three factors that are demand for success, comfort and respect. The demand for success refers to that peoples' constantly wishing for being successful and talented, and when this does not happen, it makes them feel inadequate, depressed and sad. The demand for comfort refers to that the conditions in which people live are easy, organized and able to fulfill his wishes and when this does not happen, it leads to emotions such as depression, anger, intolerance, etc. Lastly, demand for respect can be explained as that people are treated with respect and kindness, and when this does not happen, it causes anger and hatred (Ellis, 1979; Çivitci, 2006). Bedel (2014) found that irrational beliefs are a predictor of coping strategies and also found that there was a positive relationship between the negative coping dimension and the demand for 
comfort, and that the demand for comfort was an important predictor of negative coping. Kiliçarslan and Atıcı (2010) found that the demand for success and comfort is a greater predictor of aggression than the demand for respect. In parallel to this, bullying tendency has a negative relationship with irrational beliefs (Şahin, \& Sarı, 2010). In addition, bullying has been found to be associated with cognitive distortion that includes self-centered attitudes, mislabeling, assuming the worst, and blaming others sub-dimensions (Bombay, 2002). However, irrational belief in not tolerating the blocking of the rules has been found to predict especially physical aggression (Fives, Kong, Fuller, \& DiGiuseppe, 2011). This situation raises attention to evaluate the attitude towards aggression and violence while addressing bullying.

Adolescents who believe that aggression is an appropriate (relational and physical) response were reported more aggressive behavior than adolescents who believe that aggression is not an acceptable response (Werner \& Nixon, 2005). Schwartz et al. (1998) found that proactive aggression was associated with positive outcome expectations, high levels of ambitious social behavior, and low obedience. In addition, reactive aggression is associated with hostile attributional tendencies and frequent victimization. In the light of all that information, when an evaluation within the cognitive framework arises questions on the role of moral disengagement, attitudes towards violence, and irrational beliefs in predicting bullying cognition.

In this study, it is aimed to investigate whether moral disengagement, attitude towards violence and irrational beliefs play a role in predicting cognition related to bullying. The research questions in line with this main purpose of the research are as follows:

1) Do moral disengagement, attitude towards violence and irrational beliefs significantly predict bullying cognition?

2) Do the participants' moral disengagement, attitude towards violence, irrational beliefs and bullying cognition differ significantly according to gender?

\section{Method}

\subsection{Research Design}

This study was designed according to correlational research techniqes as it aims to examine the predictive effects of independent variables on the dependent variable. So, the relationships between the variables were tested by regression analysis and independent samples t-test.

\subsection{Participants}

The population of the study consists of adolescents aged between 15-18, who live in Istanbul and participants were selected through convenience sampling. The sample consisted of 369 participants..

According to demographic variables, $53.4 \%$ of the participants are female $(\mathrm{N}=197)$ and $46.6 \%$ of them are male $(\mathrm{N}=172)$. In addition, $22.7 \%$ of the participants continued to the ninth grade $(\mathrm{N}=84), 39.8 \%$ to the tenth grade $(\mathrm{N}$ $=147), 28.1 \%$ to the eleventh grade $(\mathrm{N}=104)$ and $9.2 \%$ to the twelfth grade $(\mathrm{N}=34)$. Considering the distribution of the participants according to their birth order, $40.9 \%$ were the first child $(\mathrm{N}=151), 33.8 \%$ were the second child $(\mathrm{N}=125), 14.01 \%$ were the middle child $(\mathrm{N}=52)$ and $11 \%$ were the last child $(\mathrm{N}=41)$.

\subsection{Instruments}

In the study, Moral Disengagement Scale, Attitude towards Violence Scale, Irrational Beliefs Scale and Bullying Cognition Scale were utilized as data collection tools. Psychometric information about scales is given in this section.

\subsubsection{Moral Disengagement Scale}

The original form of the scale was developed by Bandura et al. (1996). It covers eight different cognitive and social situations in order to determine to what extent individuals tend to adopt moral behavior justification. These are legitimization, labeling negative behavior positively, comparing negative behavior, spreading responsibility, not taking responsibility, distorting the results, dehumanization and putting the blame on the victim. Adaptation of the scale into Turkish was carried out by Gezici-Yalçın, Şenyurt, Gültepe, and Coşkun (2016) with 285 participants. While answering the scale, a triple rating that includes agree-partially agree-disagree options is used. The scale adapted reveals a single-factor structure. Confirmatory factor analysis was performed to test the construct validity of the scale in Turkish version and it was determined that there were acceptable fit values $(\chi 2 / \mathrm{df}=2.31, \mathrm{GFI}=.79$, RMSEA $=.06, \mathrm{RMR}=.10$ ). Cronbach Alpha coefficient calculated for reliability of the scale was found as .86 and Guttman Split Half coefficient was found as .78. In line with these values, it was evaluated that the scale used to determine moral disengagement tendency is reliable and valid. 


\subsubsection{Attitudes Towards Violence Scale}

It was developed by Çetin (2011) to evaluate youth's attitudes towards violence. Validity and reliability studies were conducted with 583 participants between the ages of 14-21. The total variance explained as a result of the principal components analysis to test the construct validity was calculated as $43.826 \%$ under one factor. The item-total correlation of the scale items varies between .47 and .67. The values of goodness of fit obtained from the confirmatory factor analysis were determined to be in the acceptable range for the construct validity of the scale $(\chi 2 / \mathrm{df}=2.31, \mathrm{GFI}=.96, \mathrm{AGFI}=.94, \mathrm{CFI}=.95 \mathrm{RMSEA}=.06, \mathrm{RMR}=.0037)$. Cronbach Alpha coefficient was calculated for the reliability of the scale and this value was found as .85 . The scale consisting of a total of 10 items is five-point Likert type.

\subsubsection{Irrational Beliefs Scale for Adolescents}

It was developed to measure the irrational beliefs of adolescents in terms of demands for comfort, respect and success. The reliability and validity studies were conducted with data obtained from 694 participants. The scale is a five-point Likert type and consists of 8 items in the demand for success sub-dimension, 7 items in the demand for comfort sub-dimension and 6 items in the demand for respect sub-dimension. The increase in the score shows that the level of irrational belief increases. Results of the analysis of the principal components performed to test the construct validity of the scale revealed that factor loads varied between .40 and .69 , and three factors explained $33.04 \%$ of the total variance. Cronbach Alpha internal consistency coefficients of the scale were found as .71 for total score, .62 for success demand sub-dimension, .61 for comfort demand sub-dimension and .67 for respect demand sub-dimension. Corrected item total correlation coefficients of the scale ranged between .28 and .68 . In line with these findings, the Irrational Beliefs Scale for Adolescents was found to be valid and reliable (Çivitci, 2016).

\subsubsection{Cognition of Bullying Scale}

This scale, in which cognition related to bullying is evaluated, was developed by Gökkaya and Sütcü (2015) with the participation of 1740 students attending secondary school. In this study, the Cronbach Alpha internal consistency coefficient of the scale was calculated as .90 . In the first stage, items, which were developed as 25 items originally, with low item-total correlations, and items that decrease the internal consistency, were removed and analyzes were conducted with 22 items. To test the construct validity of the scale, principal components analysis was performed by using varimax rotation. As a result, it was determined that the scale showed a three-factor structure, $19.02 \%$ of the variance of first factor, $18.9 \%$ of the variance of the second factor, $11.42 \%$ of the variance of the third factor and $48.73 \%$ of the variance of all items. Item-factor loads vary between .31 and .74 . The Cronbach Alpha coefficient of the scale was found to be .91, which indicates that the scale has a high internal consistency. Based on these findings, the scale is valid and reliable.

\subsection{Data Analysis}

As mentioned before, this study aims to investigate the relationship of moral disengagement, attitude towards violence, and irrational beliefs with bullying cognition and to what extent participants' moral disengagement behaviors, attitudes towards violence and irrational beliefs played a role in determining the factors that may affect bullying cognition. Firstly, independent groups' $t$ test was conducted on whether the mean scores of moral disengagements, attitude towards violence, irrational beliefs and bullying cognition differ according to gender. Statistical differences were also examined in terms of effect sizes. For the differences between the groups, 0.2 indicates that the effect size is low, 0.5 indicates the moderate effect size and 0.8 shows the effect size (Cohen, 1988). Based on the main purpose of the study, hierarchical regression analysis was carried out in determining the relationship between the independent variables of the study and bullying cognition. Before proceeding to the hierarchical regression analysis, it was evaluated whether the regression analysis assumptions, normality of the distribution, multicollinearity, autocorrelation and covariance, were satisfied (Field, 2013).

\section{Results}

\subsection{Demographic Findings}

The means, standard deviations and standard errors of the mean obtained from Moral Disengagement, Attitudes towards Violence, Irrational Beliefs and Bullying Cognition scales based on gender, grade level and birth order are presented in Table 1, 2, and 3. The mean score of female students towards violence is $25.13(S D=8.46)$, while the mean score of male students is $27.42(S D=7.93)$. Again, the irrational beliefs mean score of female students is $61.54(S D=8.91)$ while the mean score of male students is $64.22(S D=9.45)$. While the moral disengagement mean score of male students is $69.59(S D=9.40)$, the mean score of female students is $73.38(S D=8.73)$. Bullying cognition mean score is $76.59(S D=10.85)$ for female students, while the mean score for male students is 70.88 
$(S D=12.09)$.

Table 1. Means, standard deviation and standard error of mean of scales by gender

\begin{tabular}{ccccccccc}
\hline & \multicolumn{2}{c}{ MD } & \multicolumn{2}{c}{ ATV } & \multicolumn{2}{c}{ IB } & \multicolumn{2}{c}{ CBUL } \\
\hline & female & male & female & male & female & male & female & male \\
\hline $\mathrm{N}$ & 197 & 172 & 197 & 172 & 197 & 172 & 197 & 172 \\
$M$ & 73.381 & 69.593 & 25.127 & 27.419 & 61.538 & 64.221 & 76.589 & 70.884 \\
$\mathrm{SE}$ of $M$ & 0.622 & 0.716 & 0.603 & 0.605 & 0.635 & 0.721 & 0.773 & 0.922 \\
$\mathrm{SD}$ & 8.725 & 9.396 & 8.462 & 7.932 & 8.913 & 9.451 & 10.851 & 12.093 \\
\hline
\end{tabular}

Note. N: Sample size, M: Mean, SEM: Standard error of mean, SD: Standard deviation, MD: Moral disengagement, ATV: Attitudes towards violence, IB: Irrational beliefs, CBUL: Cognition of bullying.

According to the grade level of the participants, moral disengagement, the attitude towards violence, irrational beliefs and bullying cognition mean scores and standard deviations are as follows: The attitude towards violence mean score was estimated as $26.62(S D=9.16)$ for ninth grade students, $25.37(S D=7.83)$, for the tenth-grade students, $27.26(S D=8.21)$ for the eleventh-grade students and $25.44(S D=8.08)$ for the twelfth-grade students. The moral disengagement mean score was calculated as $71.23(S D=9.62)$ for the ninth-grade students, $72.48(S D$ $=9.07)$ for the tenth-grade students, $71.32(S D=9.01)$ for the eleventh-grade students and $69.74(S D=9.60)$ for the twelfth-grade students. The irrational beliefs mean score was calculated as $64.49(S D=10.57)$ for the ninth-grade students, $61.83(S D=8.49)$ for the tenth-grade students, $62.64(S D=9.56)$ for the eleventh-grade students and $63.21(S D=7.60$ for the twelfth-grade students. Bullying cognition mean scores were calculated as $73.77(S D=11.62)$ for the ninth-grade students, $73.61(S D=13.15)$ for the tenth-grade students, $74.34(S D=9.46)$ for the eleventh-grade students and $74.44(S D=12.75)$ for the twelfth-grade students.

Table 2. Means, standard deviation and standard error of mean of scales by grade level

\begin{tabular}{cccccc}
\hline & & $\mathrm{N}$ & $M$ & $\mathrm{SD}$ & SE of $M$ \\
\hline \multirow{4}{*}{ MD } & Ninth-grade & 84 & 71.23 & 9.62 & 1.05 \\
& Tenth-grade & 147 & 72.48 & 9.07 & 0.750 \\
& Eleventh-grade & 104 & 71.32 & 9.01 & 0.88 \\
& Twelfth-grade & 34 & 69.74 & 9.60 & 1.65 \\
\hline \multirow{4}{*}{ ATV } & Tenth-grade & 84 & 26.62 & 9.16 & 0.99 \\
& Eleventh-grade & 147 & 25.37 & 7.83 & 0.65 \\
& Twelfth-grade & 104 & 27.26 & 8.21 & 0.81 \\
& Tenth-grade & 34 & 25.44 & 8.08 & 1.39 \\
\hline \multirow{4}{*}{ IB } & Tenth-grade & 84 & 64.49 & 10.57 & 1.15 \\
& Eleventh-grade & 147 & 61.83 & 8.49 & 0.70 \\
& Twelfth-grade & 104 & 62.64 & 9.56 & 0.94 \\
& Tenth-grade & 34 & 63.21 & 7.60 & 1.30 \\
\hline \multirow{4}{*}{ CBUL } & Tenth-grade & 84 & 73.77 & 11.62 & 1.27 \\
& Eleventh-grade & 147 & 73.61 & 13.15 & 1.09 \\
& Twelfth-grade & 104 & 74.34 & 9.46 & 0.93 \\
& Tenth-grade & 34 & 74.44 & 12.75 & 2.19 \\
\hline
\end{tabular}

Note. N: Sample size, M: Mean, SEM: Standard error of mean, SD: Standard deviation, MD: Moral disengagement, ATV: Attitudes towards violence, IB: Irrational beliefs, BUL: Cognition of bullying.

Mean scores and standard deviations of the participants' attitudes towards violence, moral disengagement, irrational beliefs and bullying cognition by birth order are presented in Table 3 . The mean score of attitudes towards violence of the first children is $27.06(S D=8.34)$, the mean of the second children is $25.61(S D=7.95)$, the mean of the third children is $25.87(S D=9.41)$ and the mean of the last children is $25.22(S D=7.58)$. Moral disengagement mean scores are $70.94(S D=9.84)$ for the first children, $71.97(S D=8.43)$ for the second children, $73.42(S D=9.30)$ for the third children and $70.73(S D=9.06)$ for the last children. The irrational beliefs mean score of the first children was $63.35(S D=8.99)$, the mean of the second children was $62.50(S D=9.13)$, the mean 
of the third children was $61.27(S D=9.69)$ and the mean of the last children was $63.54(S D=10.10)$. Bullying cognition mean scores were found as $73.85(S D=11.57)$ for the first children, $74.21(S D=11.50)$ for the second children, $75.56(S D=12.43)$ for the third children and $71.29(S D=12.52)$ for the last children.

Table 3. Means, standard deviation and standard error of mean of scales by birth order

\begin{tabular}{cccccc}
\hline & & $\mathrm{N}$ & $M$ & SD & SE of $M$ \\
\hline \multirow{4}{*}{ MD } & First child & 151 & 70.94 & 9.84 & 0.80 \\
& Second child & 125 & 71.97 & 8.43 & 0.75 \\
& Middle child & 52 & 73.42 & 9.30 & 1.29 \\
& Last child & 41 & 70.73 & 9.06 & 1.42 \\
\hline \multirow{4}{*}{ ATV } & First child & 151 & 27.06 & 8.34 & 0.68 \\
& Second child & 125 & 25.61 & 7.95 & 0.71 \\
& Middle child & 52 & 25.87 & 9.41 & 1.30 \\
& Last child & 41 & 25.22 & 7.58 & 1.18 \\
\hline \multirow{4}{*}{ IB } & First child & 151 & 63.35 & 8.99 & 0.73 \\
& Second child & 125 & 62.50 & 9.13 & 0.82 \\
& Middle child & 52 & 61.27 & 9.69 & 1.34 \\
& Last child & 41 & 63.54 & 10.10 & 1.58 \\
\hline \multirow{4}{*}{ CBUL } & First child & 151 & 73.85 & 11.57 & 0.94 \\
& Second child & 125 & 74.21 & 11.50 & 1.03 \\
& Middle child & 52 & 75.56 & 12.43 & 1.72 \\
& Last child & 41 & 71.29 & 12.52 & 1.96 \\
\hline
\end{tabular}

Note. N: Sample size, M: Mean, SEM: Standard error of mean, SD: Standard deviation, MD: Moral disengagement, ATV: Attitudes towards violence, IB: Irrational beliefs, BUL: Cognition of bullying.

\subsection{Findings on Gender Differences of Regarding Moral Disengagement, Attitudes Towards Violence, Irrational Beliefs and Bullying Cognition}

The participants' mean scores of moral disengagements, attitude towards violence, irrational beliefs and bullying cognition were compared. Significant differences were found between the mean scores of female and male participants. The mean score differences according to gender were analyzed by independent groups $t$ test and the findings are given in Table 4.

Female participants' moral disengagement mean scores are significantly higher than male participants and the effect size is medium $(t=4.013, p<.001, d=0.419)$. Accordingly, it can be stated that female participants tend to be more morally distanced than male participants.

Male participants' mean score of attitudes towards violence is significantly higher than female participants and the effect size is low $(t=-2.672, p=.008, d=-0.279)$. Based on this finding, it can be said that males have higher attitudes towards violence than female participants.

Another variable is irrational beliefs. Irrational beliefs of male participants are significantly higher than female participants and their effect size is low $(t=-2.804, p=.005, d=-0.293)$. Male participants have more irrational beliefs than female participants.

Considering the cognition of bullying, female participants were found to have a significantly higher mean score than male participants, and the effect size was moderate $(t=4.776, p<.001, d=0.498)$. It is seen that female participants have more bullying cognition than male participants. 
Table 4. The findings of independent sample t-test on moral disengagement, attitudes towards violence, irrational beliefs and cognition of bullying in terms of gender

\begin{tabular}{ccccccccc}
\hline & & $\mathrm{N}$ & $M$ & $\mathrm{SD}$ & $\mathrm{SE}$ & $\mathrm{t}$ & $\mathrm{p}$ & Cohen's d \\
\hline \multirow{2}{*}{ MD } & female & 197 & 73.381 & 8.725 & 0.622 & 4.013 & $<.001$ & 0.419 \\
& male & 172 & 69.593 & 9.396 & 0.716 & & & \\
\hline \multirow{2}{*}{ ATV } & female & 197 & 25.127 & 8.462 & 0.603 & -2.672 & .008 & -0.279 \\
& male & 172 & 27.419 & 7.932 & 0.605 & & & \\
\hline \multirow{2}{*}{ IB } & female & 197 & 61.538 & 8.913 & 0.635 & -2.804 & .005 & -0.293 \\
& male & 172 & 64.221 & 9.451 & 0.721 & & & \\
\hline \multirow{2}{*}{ CBUL } & female & 197 & 76.589 & 10.851 & 0.773 & 4.776 & $<.001$ & 0.498 \\
& male & 172 & 70.884 & 12.093 & 0.922 & & & \\
\hline
\end{tabular}

Note. significant level is .05, MD: moral disengagement, ATV: attitudes towards violence, IB: irrational beliefs, CBUL: cognition of bullying.

\subsection{Findings on Hierarchical Regression Analysis Assumptions}

Firstly, in order to determine whether regression analysis assumptions are provided or not, the skewness and kurtosis coefficients are examined whether they are between -2 and +2 to test the normality of the distribution (Field, 2013). Based on scale scores obtained from the participants, the fact that the skewness and kurtosis coefficients are between -2 and +2 indicate the distribution is normal. Autocorrelation between the errors, the second assumption, was examined by Durbin-Watson test. The test result being around 2 indicates that the errors are independent from each other (Field, 2013). Durbin-Watson value was calculated 2.23 and this assumption was met. Tolerance value and VIF values were calculated to test the multicollinearity, which is another assumption. It was found that this assumption was also provided when the tolerance value was above 0.1 and VIF values were below 10. Finally, the scatter plot was examined to check homoscedasticity and linearity assumption (Field, 2013) and this assumption was also met. Then, hierarchical regression analysis was performed.

Table 5. Skewness and kurtosis coefficients of variables, tolerance values and VIF

\begin{tabular}{ccccc}
\hline & MD & ATV & IB & CBUL \\
\hline $\mathrm{N}$ & 369 & 369 & 369 & 369 \\
$M$ & 71.62 & 26.20 & 62.79 & 73.93 \\
SD & 9.23 & 8.29 & 9.25 & 11.78 \\
Skewness & -0.15 & 0.09 & 0.14 & -0.89 \\
SE of skewness & 0.13 & 0.13 & 0.13 & 0.13 \\
Kurtosis & -0.13 & -0.32 & 0.003 & 0.06 \\
SE of kurtosis & 0.25 & 0.25 & 0.25 & 0.25 \\
Tolerance & 0.79 & 0.84 & 0.23 & - \\
VIF & 1.27 & 1.19 & 4.28 & - \\
\hline
\end{tabular}

\subsection{Relationship Between Independent Variables and Bullying Cognition-Hierarchical Regression Analysis Findings}

Hierarchical regression analysis was conducted to examine the relationship between attitudes towards violence, moral disengagement and irrational beliefs, and the demands for comfort and for success sub-dimensions with bullying cognition.

As a result of the analysis, 5 different models were obtained. In the first model, it was seen that moral disengagement significantly predicted bullying cognition. Accordingly, the $26 \%$ change in bullying cognition is explained by one unit change in moral disengagement $\left(\Delta \mathrm{R}^{2}=.26, F_{(1,367)}=133.21 p<.001, \beta=.52, t=11.54\right)$.

In the second model, it was found that moral disengagement and attitude towards violence significantly predicted bullying cognition. It was determined that both two variables together explained a $29 \%$ change in bullying cognition by one unit change $\left(\Delta \mathrm{R}^{2}=.29, F_{(2,366)}=77.26, p<.001, \beta_{1}=.45, t_{1}=9.60 ; \beta_{2}=-.19, t_{2}=-3.99\right)$.

In the third model, the sub-dimension of irrational beliefs, demand for comfort was another variable that significantly predicted bullying cognition along with moral disengagement and attitude towards violence. It was seen that this model explained $31 \%$ of change in bullying cognition $\left(\Delta \mathrm{R}^{2}=.31, F_{(3,365)}=55.97 p<.001, \beta_{1}=.41\right.$, 
$\left.t_{1}=8.36 ; \beta_{2}=-.16, t_{2}=-3.49 ; \beta_{3}=-.15, t_{3}=-3.12\right)$.

In the fourth model, along with the sub-dimension of irrational beliefs, the demand for success was included, and it was determined that these two variables significantly predicted bullying cognition along with the moral disengagement and attitude towards violence. Moral disengagement, attitude towards violence, and the demand for comfort and success were found to explain $32 \%$ of change in bullying cognition $\left(\Delta \mathrm{R}^{2}=.32, F_{(4,364)}=44.57, p\right.$ $\left.<.001, \beta_{1}=.40, t_{1}=8.23 ; \beta_{2}=-.15, t_{2}=-3.21 ; \beta_{3}=-.13, t_{3}=-2.74 ; \beta_{4}=-.12, t_{4}=-2.72\right)$.

Table 6. Findings on hierarchical regression analysis on predictors of bullying cognition

\begin{tabular}{|c|c|c|c|c|c|c|c|c|c|c|}
\hline & & $\mathrm{R}$ & $\Delta \mathrm{R}^{2}$ & $\mathrm{~F}$ & $p$ & $\mathrm{~B}$ & SE B & $\beta$ & $t$ & $p$ \\
\hline \multirow{2}{*}{1} & Model & 0.52 & 0.26 & 133.21 & $<.001$ & 26.746 & 4.122 & & 6.489 & $<.001$ \\
\hline & Moral disengagement & & & & & 0.659 & 0.057 & 0.516 & 11.542 & $<.001$ \\
\hline \multirow{3}{*}{2} & Model & 0.55 & 0.29 & 77.26 & $<.001$ & 39.763 & 5.195 & & 7.655 & $<.001$ \\
\hline & Moral disengagement & & & & & 0.574 & 0.060 & 0.450 & 9.596 & $<.001$ \\
\hline & Attitudes towards violence & & & & & -0.266 & 0.067 & -0.187 & -3.987 & $<.001$ \\
\hline \multirow{4}{*}{3} & Model & 0.56 & 0.31 & 55.97 & $<.001$ & 48.645 & 5.872 & & 8.284 & $<.001$ \\
\hline & Moral disengagement & & & & & 0.518 & 0.062 & 0.405 & 8.362 & $<.001$ \\
\hline & Attitudes towards violence & & & & & -0.233 & 0.067 & -0.164 & -3.488 & $<.001$ \\
\hline & Comfort demand & & & & & -0.315 & 0.101 & -0.147 & -3.116 & 0.002 \\
\hline \multirow{5}{*}{4} & Model & 0.57 & 0.32 & 44.57 & $<.001$ & 53.458 & 6.084 & & 8.787 & $<.001$ \\
\hline & Moral disengagement & & & & & 0.506 & 0.061 & 0.397 & 8.234 & $<.001$ \\
\hline & Attitudes towards violence & & & & & -0.213 & 0.067 & -0.150 & -3.205 & 0.001 \\
\hline & Comfort demand & & & & & -0.277 & 0.101 & -0.129 & -2.735 & 0.007 \\
\hline & Success demand & & & & & -0.261 & 0.096 & -0.121 & -2.722 & 0.007 \\
\hline
\end{tabular}

\section{Discussion}

In this section, findings were discussed with previous studies. When findings are revisited, it was found that moral disengagement, attitudes towards violence and irrational beliefs predicted the bullying cognition significantly as the main finding of the study. Also, females had higher mean score of moral disengagement and of bullying cognition than males. On the other hand, males had higher mean score of attitudes towards violence and of irrational beliefs than females.

Talking about violence means addressing the complex issues of morality, ideology and culture (World Health Organization, 2002). In this regard, addressing issues such as bullying, moral disengagement, attitudes towards violence, and irrational beliefs can provide a framework for understanding and making this idea understandable. Within the scope of this study, the factors that may affect the course of the formation of violence in cognitive dimension before being transformed into behavior were examined. How and in what direction the role of cognitive factors in predicting bullying cognition come true is discussed. In addition, the differences of moral disengagement, attitude towards violence, irrational beliefs and bullying cognition by gender were also examined.

In this study, the role of moral disengagement, attitude towards violence and irrational beliefs as predictors of bullying cognition were examined. As a result, one of the predictors of bullying cognition is moral disengagement. Especially when it comes to traditional bullying, seeing that the victim is suffering and the desire to move away from this situation brings about moral disengagement (Perren \& Gutzwiller-Helfenfinger, 2012). Studies show that students experiencing more moral disengagement are more likely to bully (Hymel et al., 2005; Menesini, Palladino, \& Nocentini, 2015; Menesini et al., 2003; Thornberg, Pozzoli, Gini, \& Jungert, 2015). Moral disengagement was positively associated with both direct and indirect bullying (Bussey, Quinn, \& Dobson, 2015; Kokkinos \& Kipritsi, 2018; Turner, 2008). In fact, Stein and Jimerson (2020) stated that moral disengagement should be investigated to be taken into consideration in anti-bullying programs. While beliefs and attitudes towards supporting the use of violence are positively associated with bullying, having a non-violent attitude is associated with low level of bullying (Espelage, Bosworth, \& Simon, 2001). Thornberg and Jungert (2014) found that bullying is related to attribution to victim and moral justification among moral disengagement mechanisms. Bjärehed, Thornberg, Wänström, and Gini (2020) studied the relationship between moral disengagement and direct and indirect bullying and pro-bullying behavior of students attending secondary school. They found that both direct and indirect bullying is related to moral legitimization, optimistic labeling, advantageous comparison, spreading responsibility, displacement of responsibility, and distorting results. It has been observed that 
pro-bullying behavior is not only related to advantageous comparison but also with other moral disengagement sub-dimensions. They also found that all of them were predicted by the victim-oriented loading. The existence of a relationship between the victim's perspective and bullying reminds of the importance of empathy. While there is a negative relationship between bullying and empathy, there is a positive relationship with moral disengagement. Males with low levels of emotional empathy have been associated with moral disengagement, which increases participation in bullying. For females, when both cognitive and emotional empathy scores are low, the moral disengagement score that triggers bullying increases (Kokkinos \& Kipritsi, 2018). Witnessing violence for a long time also increases desensitization (Mrug, Madan \& Windle, 2006), causes the behavior of the attacker and its effects on the victim less underestimated (Carnagey, Anderson \& Bushman, 2017).

In the current study, it was also found that moral disengagement and attitude towards violence significantly predicted bullying cognition. Cognitive information is an important source for attitudes and affects behavior (Olson \& Maio, 2003). When a person commits violence, he/she can be reinforced, expect reward, and moreover, violence can be normalized (Patel, 2012). It has been seen that having a positive attitude towards aggression is the predictor of destructive and aggressive behavior in school (McConville \& Cornell, 2003). In addition, those who stated that they used violence to solve the problems they encountered in school were found to have higher attitudes towards violence than those who never applied (Balkıs, Duru, \& Buluş, 2005). Aggressive attitudes were found to be positively correlated with bullying behavior, which was evaluated based on both self-report and peer-report (Eliot \& Cornell, 2009). Normative beliefs about aggression predict aggression (Ang, Tan, \& Talib-Mansor, 2011; Huesmann \& Guerra, 1997; Werner \& Nixon, 2005). Perry, Perry, and Rasmussen (1986) found that aggressive children believe that more aggression will bring tangible rewards and protect them from ill-treatment than non-aggressive ones. Slaby and Guerra (1988) state that aggressive participants have been found to have beliefs that support the use of aggression, including seeing aggression legitimate, believing that it will increase self-esteem, thinking that the victim will not be harmed, and believing that it will hinder the negative image.

As a result of the study, it was found that irrational beliefs, demand for comfort and for success were predictors of bullying along with moral disengagement and attitude towards violence while the demand for respect was not found as a predictor. Consistent with the results of this study, Kılıçarslan and Atıc1 (2010) found that the demand for success and comfort is a greater predictor of aggression than the demand for respect. The bully may not need to be approved by important people in the community. They are already popular among their friends because of bullying (Aluede et al., 2008; Perdew, 2015). There may be a tendency to continue bullying behavior in order to keep themselves popular. In such a situation, with the support of the environment, the action of those who bullied may result in attributing a positive meaning to bullying. Hence, irrational beliefs play a role in bullying cognition and their replacement with positive alternatives is a matter of discussion.

Another result of the study showed that female students have higher moral disengagement tendencies than male students and cognition of female students about bullying was higher than male students. For irrational beliefs and attitudes towards violence, it was observed that the mean score of males was higher while scores of moral disengagement and bullying cognition of females are higher. Also, the moral disengagement score of the females was higher. Related studies stated that males are more prone to moral disengagement than females (Caravita et al., 2014; De Caroli \& Sagone, 2014; Turner, 2008), which is not consisted with the results of this study. Such a difference can be evaluated in the context of the developmental characteristics of the participants. Again, that males participate more in bullying events attracts attention as a result of many studies (Erdur-Baker, 2010; Feigenberg et al., 2008; Robson \& Witenberg, 2013; Turner, 2008). Beyond that, it seems that being a male increases the strength of the relationship between moral disengagement and bullying (van Noorden, Haselager, Cillessen, \& Bukowski, 2014; Wang, Lei, Liu, \& Hu, 2016). Menesini et al. (2015) found that males involved in bullying had higher moral disengagement scores. In parallel with moral disengagement mechanisms; in the literature, it is seen that males' cognition scores about bullying are higher (Gökkaya \& Sütçü, 2015; Kılıç, 2019).

\subsection{Limitations and Recommendations for Future Research}

The study group is limited to the 15-18 age group. Making a comparison with the results that can be obtained from a different study group during the first adolescence period may be an important issue for understanding and explaining the variables. Cognitive assessments were handled within the limits of quantitative research approach.

In this study, it has been observed that moral disengagement, attitude towards violence, irrational beliefs -the demands for comfort and for success sub-dimension- are as a predictor of bullying. Within the scope of the study, participants between the ages of 15-18 were studied. In the studies that will reflect different age groups-children, early adolescence, and early adulthood periods-dynamics of moral disengagement, attitudes towards violence and irrational beliefs can be examined. In order to understand these variables in depth and to make sense of the 
prominent elements in bullying experiences, an understanding of bullying cognition can be revealed through case studies or phenomenological studies, which are designed with qualitative research approach.

Suggestions for preventive and intervention activities related to bullying can be listed for school counselors. Firstly, it is an important issue to focus on the cognitive dimension in preventive studies on bullying. However, cognitive behavioral-based programs that will change the perspective of bullying and violence are thought to be beneficial in the intervention studies both for those who exhibit bullying and for those exposed to bullying.

\section{References}

Aluede, O., Adeleke, F., Omoike, D., \& Afen-Akpaida, J. (2008). A review of the extent, nature, characteristics and effects of bullying behaviour in schools. Journal of Instructional Psychology, 35(2), 151-159.

Ang, R. P., Tan, K. A., \& Talib-Mansor, A. (2011). Normative beliefs about aggression as a mediator of narcissistic exploitativeness and cyberbullying. Journal of Interpersonal Violence, 26(13), 2619-2634. https://doi.org/10.1177/0886260510388286

Baldry, A. C. (2004). 'What about bullying?' An experimental field study to understand students' attitudes towards bullying and victimization in Italian middle schools. British Journal of Educational Psychology, 74(4), 583-598. https://doi.org/10.1348/0007099042376391

Balkıs, M., Duru, E., \& Buluş, M. (2005). The relationship between attitudes toward violance and self efficacy media beliefs toward violance peer group and sense of belonging to school. Ege Journal of Education, 6(2), 81-97.

Bandura, A. (1999). Moral disengagement in the perpetration of inhumanities. Personality and Social Psychology Review, 3(3),193-209. https://doi.org/10.1207/s15327957pspr0303_3

Bandura, A. (2002). Selective moral disengagement in the exercise of moral agency. Journal of Moral Education. 31(2), 101-119. https://doi.org/10.1080/0305724022014322

Bandura, A., Barbaranelli, C., Caprara, G. V., \& Pastorelli, C. (1996). Mechanisms of moral disengagement in the exercise of moral agency. Journal of Personality and Social Psychology, 71(2), 364-374. https://doi.org/10.1037/0022-3514.71.2.364

Bedel, A. (2014). Coping strategies as the predictor of irrational beliefs among adolescents. Education and Science, 39(176), 237-246. https://doi.org/10.15390/EB.2014.3518

Bjärehed, M., Thornberg, R., Wänström, L., \& Gini, G. (2020). Mechanisms of moral disengagement and their associations with indirect bullying, direct bullying, and pro-aggressive bystander behavior. The Journal of Early Adolescence, 40(1), 28-55. https://doi.org/10.1177/0272431618824745

Bombay, K.B. (2002). The relationship between self-serving cognitive distortions and bullying behaviours among elementary school children (Unpublished master thesis). Brock University Faculty of Education.

Budak, S. (2009). The dictionary of psychology. Ankara: Bilim ve Sanat.

Bussey, K., Quinn, C., \& Dobson, J. (2015). The moderating role of empathic concern and perspective taking on the relationship between moral disengagement and aggression. Merrill-Palmer Quarterly, 61(1), 10-29. https://doi.org/10.13110/merrpalmquar1982.61.1.0010

Caravita, S. C., Sijtsema, J. J., Rambaran, J. A., \& Gini, G. (2014). Peer influences on moral disengagement in late childhood and early adolescence. Journal of Youth and Adolescence, 43(2), 193-207. https://doi.org/10.1007/s10964-013-9953-1

Carnagey, N. L., Anderson, C. A., \& Bushman, B. J. (2007). The effect of video game violence on physiological desensitization to real-life violence. Journal of Experimental Social Psychology, 43(3), 489-496. https://doi.org/10.1016/j.jesp.2006.05.003

Çetin, H. (2011). The validity and reliability for the adolescents' attitudes toward violence scale. Elementary Education Online, 10(1), 68-79.

Çivitci, A. (2006). Irrational beliefs in adolescents: An investigation according to socio-demographic variables. Pamukkale University Journal of Education, 19(19), 7-17.

Çivitci, A. (2016). Development of irrational beliefs scale for adolescents: Validity and reliability studies. Journal of Turkish Psychological Counseling and Guidance, 3(25), 69-80.

Cohen, J. (1988). Statistical power analysis for the behavioural sciences (2nd ed.). New York: Academic Press. 
De Caroli, M. E., \& Sagone, E. (2014). Mechanisms of moral disengagement: An analysis from early adolescence to youth. Procedia-Social and Behavioral Sciences, 140, 312-317. https://doi.org/10.1016/j.sbspro.2014.04.426

Eliot, M., \& Cornell, D. G. (2009). Bullying in middle school as a function of insecure attachment and aggressive attitudes. School Psychology International, 30(2), 201-214. https://doi.org/10.1177/0143034309104148

Ellis, A. (1979). Toward a new theory of personality. In A. Ellis, \& M. Whiteley (Eds.), Theoretical and empirical foundations of rational-emotive therapy (pp. 7-32). California: Brooks Cole Publishing Company.

Ellis, A. (2000). Rational emotive bahaviour therapy. In R. Nelson-Jones (Eds.), Six Key approaches to counselling and therapy (pp. 181-227). London: Continuum. https://doi.org/10.1023/A:1007709720638

Erdur-Baker, O. (2010). Cyberbullying and its correlation to traditional bullying, gender and frequent and risky usage of internet-mediated communication tools. New Media and Society, 12(1), 109-125. https://doi.org/10.1177/1461444809341260

Espelage, D. L., Bosworth, K., \& Simon, T. R. (2001). Short-term stability and prospective correlates of bullying in middle-school students: An examination of potential demographic, psychosocial, and environmental influences. Violence and Victims, 16(4), 411-426. https://doi.org/10.1891/0886-6708.16.4.411

Feigenberg, L. F., King, M. S., Barr, D. J., \& Selman, R. L. (2008). Belonging to and exclusion from the peer group in schools: Influences on adolescents' moral choices. Journal of Moral Education, 37(2), 165-184. https://doi.org/10.1080/03057240802009306

Field, A. (2013). Discovering statistics using SPSS. Sage Publication.

Fives, C. J., Kong, G., Fuller, J. R., \& DiGiuseppe, R. (2011). Anger, aggression, and irrational beliefs in adolescents. Cognitive Therapy and Research, 35(3), 199-208. https://doi.org/10.1007/s10608-009-9293-3

Forsberg, C., Thornberg, R., \& Samuelsson, M. (2014). Bystanders to bullying: fourth-to seventh-grade students' perspectives on their reactions. Research Papers in Education, 29(5), 557-576. https://doi.org/10.1080/02671522.2013.878375

Frey, K. S., Hirschstein, M. K., Edstrom, L. V., \& Snell, J. L. (2009). Observed reductions in school bullying, nonbullying aggression, and destructive bystander behavior: A longitudinal evaluation. Journal of Educational Psychology, 101(2), 466-481. https://doi.org/10.1037/a0013839

Führ, M. (2002). Coping humor in early adolescence. Humor: International Journal of Humor Research, 57(3) 283-304. https://doi.org/10.1515/humr.2002.016

Gezici-Yalçın, M., Şenyurt, A. Y., Gültepe, B., \& Coşkun, H. (2016). Turkish adaptation of moral disengagement scale. Kalem International Journal of Education and Human Sciences, 6(1), 309-332. https://doi.org/10.23863/kalem.2017.63

Gökkaya, F., \& Sütcü, S. T. (2015). Development and evaluation of psychometric characteristics of the Inventory of Cognitions Related Bullying for Children. Anatolian Journal of Psychiatry, 16(Special issue 1), 54-63. https://doi.org/10.5455/apd.174346

Houndoumadi, A., \& Pateraki, L. (2001). Bullying and bullies in Greek elementary schools: Pupils' attitudes and teachers'/parents' awareness. Educational Review, $\quad$ 53(1), https://doi.org/10.1080/00131910120033619

Huesmann, L. R., \& Guerra, N. G. (1997). Children's normative beliefs about aggression and aggressive behavior. Journal of Personality and Social Psychology, 72(2), 408-419. https://doi.org/10.1037/0022-3514.72.2.408

Hymel, S., Rocke-Henderson, N., \& Bonanno, R. A. (2005). Moral disengagement: A framework for understanding bullying among adolescents. Journal of Social Sciences, 8(1), 1-11.

Kılıç, K. M. (2019). Relationships between digital game addiction, bullying cognitions and empathy levels in adolescents. Elementary Education Online, 18(2), 549-562. https://doi.org/10.17051/ilkonline.2019.562015

Kılıçarslan, S., \& Atıcı, M. (2010). The relationships between irrational beliefs and aggressiveness in adolescent. Çukurova University Journal of Social Sciences Institute, 19(3), 113-130.

Kokkinos, C. M., \& Kipritsi, E. (2018). Bullying, moral disengagement and empathy: Exploring the links among early adolescents. Educational Psychology, 38, 535- 552. https://doi.org/10.1080/01443410.2017.1363376 
Kuasandra, M. K., Sunawan, S., \& Japar, M. (2020). The effect of moral disengagement on bullying behavior tendency with empathy as a mediator on students in Pekalongan City. Jurnal Bimbingan Konseling, 9(2), 103-110.

McConville, D. W., \& Cornell, D. G. (2003). Aggressive attitudes predict aggressive behavior in middle school students. Journal of Emotional and Behavioral disorders, 11(3), 179-187. https://doi.org/10.1177/10634266030110030501

Menesini, E., Palladino, B. E., \& Nocentini, A. (2015). Emotions of moral disengagement, class norms, and bullying in adolescence: A multilevel approach. Merrill-Palmer Quarterly, 61(1), 124-143. https://doi.org/10.13110/merrpalmquar1982.61.1.0124

Menesini, E., Sanchez, V., Fonzi, A., Ortega, R., Costabile, A., \& Lo Feudo, G. (2003). Moral emotions and bullying: A cross-national comparison of differences between bullies, victims and outsiders. Aggressive Behavior: Official Journal of the International Society for Research on Aggression, 29(6), 515-530. https://doi.org/10.1002/ab.10060

Mrug, S., Madan, A., \& Windle, M. (2016). Emotional desensitization to violence contributes to adolescents' violent behavior. Journal of Abnormal Child Psychology, 44(1), 75-86. https://doi.org/10.1007/s10802-015-9986-x

Olson, J. M., \& Maio, G. R. (2003). Attitudies in social behavior. In T. Millon, \& M. J. Lerner (Eds.), Handbook of psychology (vol. 5): Personality and social psychology (pp. 299-326). New Jersey: John Wiley \& Sons, Inc. https://doi.org/10.1002/0471264385.wei0513

Olweus, D. (1993). Bullying at school. Oxford, UK: Blackwell.

Olweus, D. (1997). Bully/victim problems in school: Facts and intervention. European Journal of Psychology of Education, 12(4), 495-510. https://doi.org/10.1007/BF03172807

Padgett, S., \& Notar, C. E. (2013). Bystanders are the key to stopping bullying. Universal Journal of Educational Research, 1(2), 33-41. https://doi.org/10.13189/ujer.2013.010201

Patel, D. M. (2012). The contagion of violence: highlights from an Institute of Medicine/National Research Council workshop. Archives of Pediatrics \& Adolescent Medicine, 166(12), 1101-1102. https://doi.org/10.1001/jamapediatrics.2013.541

Perdew, L. (2015). Bullying. USA: Abdo Publishing.

Perren, S., \& Gutzwiller-Helfenfinger, E. (2012). Cyberbullying and traditional bullying in adolescence: Differential roles of moral disengagement, moral emotions, and moral values. European Journal of Developmental Psychology, 9(2), 195-209. https://doi.org/10.1080/17405629.2011.643168

Perry, D. G., Perry, L. C., \& Rasmussen, P. (1986). Cognitive social learning mediators of aggression. Child Development, 57(3), 700-711. https://doi.org/10.2307/1130347

Pişkin, M. (2002). Okul zorbalığı: Tanımı, türleri, ilişkili olduğu faktörler ve alınabilecek önlemler. Kuram ve Uygulamada Ĕgitim Bilimleri, 2(2), 531-562.

Polat, O. (2011). Çocuk ve şiddet. İstanbul: Der Yayınları.

Project of Preventing Violence Against Children. (2015). Technical support project for preventing violence against children revised early warning booklet. Ankara: European Union-Ministry of National Education.

Rigby, K. (2002). New perspectives on bullying. London: Jessica Kingsley Publishers Ltd.

Rigby, K. (2003). Stop the bullying: A handbook for schools. Aust Council for Ed Research. Camberwell: ACER

Rigby, K. (2007). Bullying in schools: And what to do about it. Camberwell: Acer Press.

Robson, C., \& Witenberg, T. R. (2013). The influence of moral disengagement, morally based self-esteem, age, and gender on traditional bullying and cyberbullying. Journal of School Violence, 12(2), 211-231. https://doi.org/10.1080/15388220.2012.762921

Şahin, M., \& Sarı, S. V. (2010). The relationship between bullying tendency with cognitive distortions and dysfunctional attitudes in adolescents. Journal of Akademik Baklş, 20, 1-14.

Schwartz, D., Dodge, K. A., Coie, J. D., Hubbard, J. A., Cillessen, A. H., Lemerise, E. A., \& Bateman, H. (1998). Social-cognitive and behavioral correlates of aggression and victimization in boys' play groups. Journal of Abnormal Child Psychology, 26(6), 431-440. https://doi.org/10.1023/A:1022695601088 
Slaby, R. G., \& Guerra, N. G. (1988). Cognitive mediators of aggression in adolescent offenders: I. Assessment. Developmental Psychology, 24(4), 580-588. https://doi.org/10.1037/0012-1649.24.4.580

Smith, J., Twemlow, S. W., \& Hoover, D. W. (1999). Bullies, victims and bystanders: a method of in-school intervention and possible parental contributions. Child Psychiatry and Human Development, 30(1), 29-37. https://oi.org/10.1023/A:1022619025074

Sokol, N., Bussey, K., \& Rapee, R. M. (2015). The effect of victims' responses to overt bullying on same-sex peer bystander reactions. Journal of School Psychology, 53(5), 375-391. https://doi.org/10.1016/j.jsp.2015.07.002

Spirito, A., Stark, L. J., \& Williams, C. (1988). Development of a brief coping checklist for use with pediatric populations. Journal of Pediatric Psychology, 13(4), 555-574. https://doi.org/10.1093/jpepsy/13.4.555

Stein, R., \& Jimerson, S. (2020). An examination of bullying roles and moral disengagement using latent analysis. Journal of School Violence, 1-14. https://doi.org/10.1080/15388220.2020.1738943

Thornberg, R. (2010). Schoolchildren's social representations on bullying causes. Psychology in the Schools, 47(4), 311-327. https://doi.org/10.1002/pits.20472

Thornberg, R. (2015). Distressed bullies, social positioning and odd victims: Young people's explanations of bullying. Children \& Society, 29(1), 15-25. https://doi.org/10.1111/chso.12015

Thornberg, R., \& Jungert, T. (2014). School bullying and the mechanisms of moral disengagement. Aggressive Behavior, 40(2), 99-108. https://doi.org/10.1002/ab.21509

Thornberg, R., Pozzoli, T., Gini, G., \& Jungert, T. (2015). Unique and interactive effects of moral emotions and moral disengagement on bullying and defending among school children. The Elementary School Journal, 116(2), 322-337. https://doi.org/10.1086/683985

Turner, R. M. (2008). Moral disengagement as a predictor of bullying and aggression: Are there gender differences? (Doctoral dissertation). ProQuest Dissertations Publishing, 3315157.

Van Noorden, T. H., Haselager, G. J., Cillessen, A. H., \& Bukowski, W. M. (2014). Dehumanization in children: The link with moral disengagement in bullying and victimization. Aggressive Behavior, 40(4), 320-328. https://doi.org/10.1002/ab.21522

Wang, X., Lei, L., Liu, D., \& Hu, H. (2016). Moderating effects of moral reasoning and gender on the relation between moral disengagement and cyberbullying in adolescents. Personality and Individual Differences, 98, 244-249. https://doi.org/10.1016/j.paid.2016.04.056

Werner, N. E., \& Nixon, C. L. (2005). Normative beliefs and relational aggression: An investigation of the cognitive bases of adolescent aggressive behavior. Journal of Youth and Adolescence, 34(3), 229-243. https://doi.org/10.1007/s10964-005-4306-3

World Health Organization. (2002). World report on violence and health: Summary. Geneva: World Health Organization.

\section{Copyrights}

Copyright for this article is retained by the author(s), with first publication rights granted to the journal.

This is an open-access article distributed under the terms and conditions of the Creative Commons Attribution license (http://creativecommons.org/licenses/by/4.0/). 